\title{
Optimal Design of Micro-Seismic Monitoring Array and Seismic Source Location Estimation for Rock Slope
}

\author{
Nuwen $\mathrm{Xu}^{1, *}$, Chun-an Tang ${ }^{2}$, Hong $\mathrm{Li}^{1}$ and Sihao $\mathrm{Wu}^{3}$ \\ ${ }^{1}$ Institute of Rock Instability and Seismicity Research, Dalian University of Technology, Dalian, Liaoning 116024, P.R. China \\ ${ }^{2}$ State Key Laboratory of Coastal and Offshore Engineering, Dalian University of Technology, Dalian, Liaoning 116024, \\ P.R. China \\ ${ }^{3}$ China Guodian Dagangshan Hydropower Development Co., Ltd., Sichuan Ya'an 625409, P.R. China
}

\begin{abstract}
For the purpose of getting a better understanding on failure mechanism of rock fracturing due to construction perturbation inside the rock slope at the right bank of Dagangshan Hydropower Station, southwest of China, a highprecision microseismic monitoring system was installed and source location data has preliminarily been investigated. The optimal design of microseismic monitoring network, especially the sensor array was investigate based on P method and Powell algorithm. The positioning accuracy of the system has been adjusted according to the artificial fixed blasting tests. The testing results show that the error in localizing microseismic source is less than $10 \mathrm{~m}$ within the scope of the sensor array, indicating that the positioning accuracy for the monitoring system deployed at the right bank slope is high. Signals from 255 microseismic events with moment magnitude ranging from -1.8 to -0.4 were recorded during the 2-month monitoring period. The cluster distribution of microseismic events such as the concentration of microseismicity inside the drainage tunnel at $1081 \mathrm{~m}$ level can directly reflect the construction progress. The present study has significantly improved the understanding of the characteristics of the failure associated with excavation inside the rock slope. It will greatly benefit the prediction on potential sliding areas and support to prevent hazards during construction phases.
\end{abstract}

Keywords: Microseismic monitoring, Optimal design, Source location error, Rock slope.

\section{INTRODUCTION}

The initiation, accumulation and growth of stress-induced cracks or fractures caused rock or rock mass damage. As we know, energy may be released as high-frequency acoustic or seismic signals from microfractures during rock loaded in testing apparatus and rock masses that are stressed in the vicinity of underground excavations. These signals provide a passive indicator of the progression of inelastic damage. Microseismic monitoring systems have been used to identify the location of such damages in rock engineering projects [13]. Microseismic monitoring is a viable non-destructive method for detecting microfracturing prior to a macroscopic rock fracture. By incorporating source localization with source parameter estimate, nowadays it is possible to visualize the development of microseismic events in 3D space. During the past two decades, the microseismic technique has gradually emerged from a pure research and technical developing means to a mainstream industrial application tool. The daily monitoring programs have greatly enhanced engineering safety and productivity of rockburstprone mines. The technique has an extensive range of application in South Africa, Canada, Japan, Austrialia and

*Address correspondence to this author at the Institute of Rock Instability and Seismicity Research, Faculty of Infrastructure Engineering, Dalian University of Technology, Dalian 116024, P.R. China; Tel: +86-0411-84708694; Fax: +86-0411-87315655; E-mails: nwxu@yahoo.cn, xvnuwen@163.com
North America. Plenty of significant achievements have been obtained in mining engineering [4-6], fluid driven fracturing [7,8], oil and gas exploration and development [9], tunneling [10], etc. In China, along with the sustained and rapid economic development, whilst more and more mines proceed to ever greater depth and into complex geological conditions and plenty of transportation and largescale hydroelectric projects are being advanced at depth, violent rock mass failure processes are to be confronted. In order to deal with such problems, microseismic monitoring technique is being used for a better understanding on deep rock mass fractures mechanism. It was used to evaluate the stability of rock masses in mines in the past decades [11, 12], and has been applied in the investigations of rockbursts in mines [13]. Its application is currently being extended to a wide variety of rock engineering problems including rockburst prediction in deep-buried tunnel [14] and failure mechanisms analysis for rock slope [2]. Some preliminary achievements have thus been obtained and the results will be utilized in this study.

Dagangshan Hydropower Station is located at midstream of Dadu River, $40 \mathrm{~km}$ away from Shimian county, about $130 \mathrm{~km}$ away from Hanyuan railway station along ChengKun railway, and nearly $72 \mathrm{~km}$ away from Luding county town, Sichuan province, P.R. China (see Fig. 1). The project is about a double-curvature dam with a maximum height of $210 \mathrm{~m}$, with a total installed capacity of $2400 \mathrm{MW}$. The 


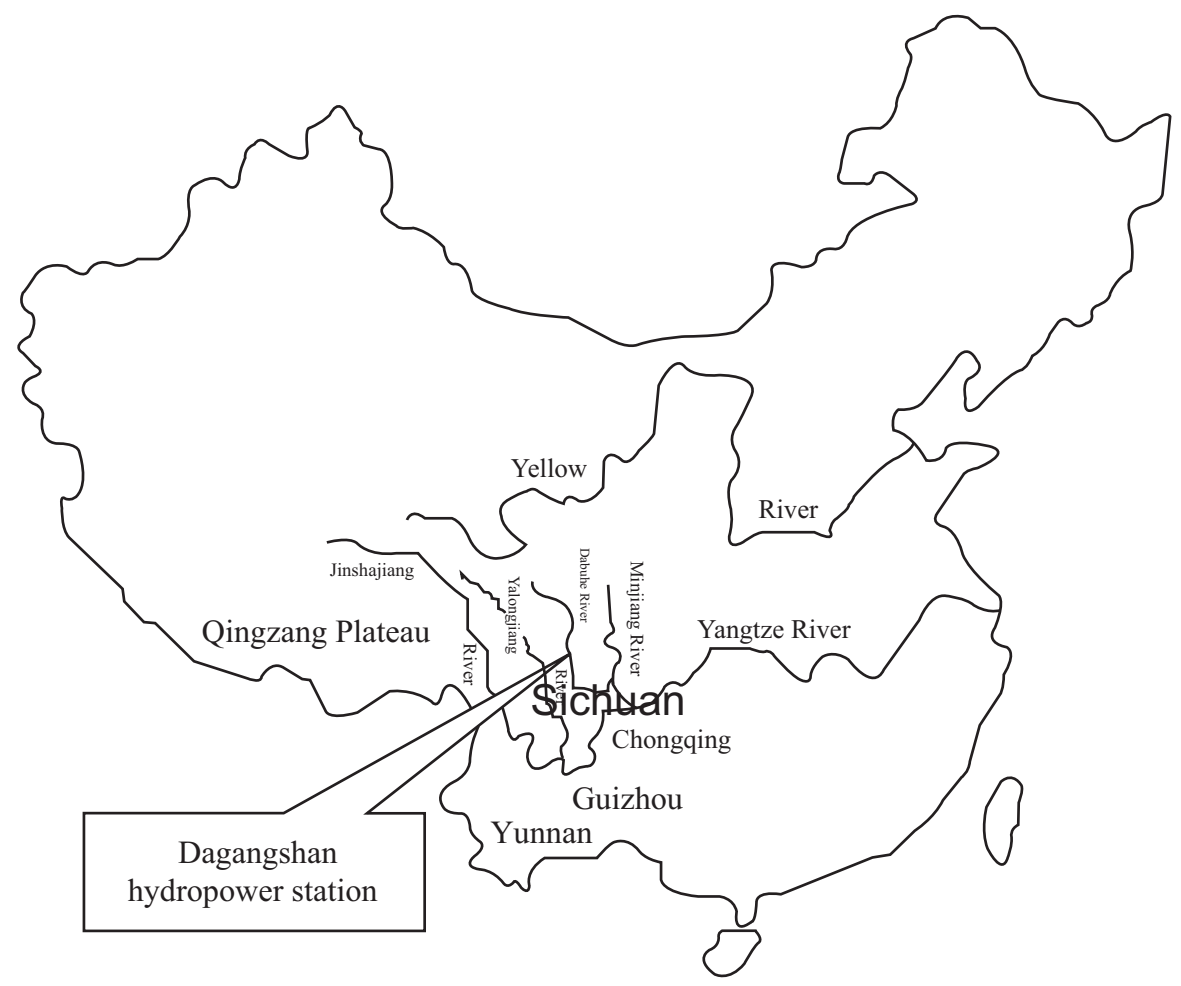

Fig. (1). Regional map of Dagangshan hydropower station.

reservoir has a normal pool level of $1130 \mathrm{~m}$, while the river's natural water level is around $960 \mathrm{~m}$. Dagangshan hydroelectric project is one of the large scale hydroelectric constructions which are currently developed along the mainstream of Dadu River. The dam is sited at high and steep mountain and within a gorge region. The river valley has a typical "V" shape. The geological structures of this area are complex due to high-steep slopes and abundant fractures in deep rock mass. Weathering and unloading of rock mass inside the right bank slope are very serious. Natural slope surface orients $\mathrm{N} 25^{\circ} \sim 35^{\circ} \mathrm{E}$ and there are variety of dikes such as $\beta_{5}\left(F_{1}\right), \gamma_{\mathrm{L} 5}, \gamma_{\mathrm{L} 6}, \beta_{169}, \beta_{170}, \beta_{202}\left(\mathrm{f}_{191}\right)$ oblique with bank slope at a small angle. Therefore, tension fractures will easily occur at such shallow slope. Plenty of investigations and excavations reveal that deformation failures have superficially occurred on the right bank slope due to stress rearrangement as a result of sapping of Dadu River. The main characteristics of slope failure are bendtension deformation, sliding-tension deformation, creeptension deformation and collapse failure partially. The layout of key water control and the right bank slope after excavation are presented in Fig. (2) [15].

In the present study, a high-precision microseismic monitoring installation manufactured by ESG (Engineering Seismology Group), Canada has been carried out since May 2010 in order to better understand the failure mechanisms of rock fracturing due to construction perturbation inside the rock slope. Taking in situ geological condition into account, $\mathrm{P}$ method (P-wave first break time method) and Powell algorithm were applied to optimize the networking arrangement of sensors. Artificial fixed blasting tests were per- formed to adjust the positioning accuracy of the system, and error analysis of microseismic source localization was thus conducted. Furthermore, preliminary micro-seismic data have been investigated. It validated that the application design and implementation of microseismic monitoring system could meet the global monitoring requirement of deep rock mass deformation and identify the excavation disturbed areas.

\section{OPTIMAL DESIGN OF SENSOR NETWORKING}

Sophisticated seismic monitoring system can today accurately record the ground motions caused by the deformations at a seismic source. Such systems are now installed at many mines, particularly in deep mines [1], rarely in rock slopes besides the left bank slope of Jinping First Stage Hydropower Station [3]. As we know, microseismic monitoring can record various signals caused by deformations at a seismic source in deep rockmass and determine tremor parameters of microseismic events, for example, shock time, hypocenter location, energy release, etc. There are many hypocentral localization approaches such as P method (P-wave first break time method), P-S (P-S wave first break time difference method) method, azimuth method, translocation mode, Geiger's method and others [16, 17].

Microseismic monitoring installation employed in the right bank rock slope of Dagangshan project adopts $\mathrm{P}$ method to locate seismic sources. The principle is that first sensors are installed to receive time difference of the starting point of $\mathrm{P}$ wave, and then two-dimensional or threedimensional positioning is performed in a particular wave 

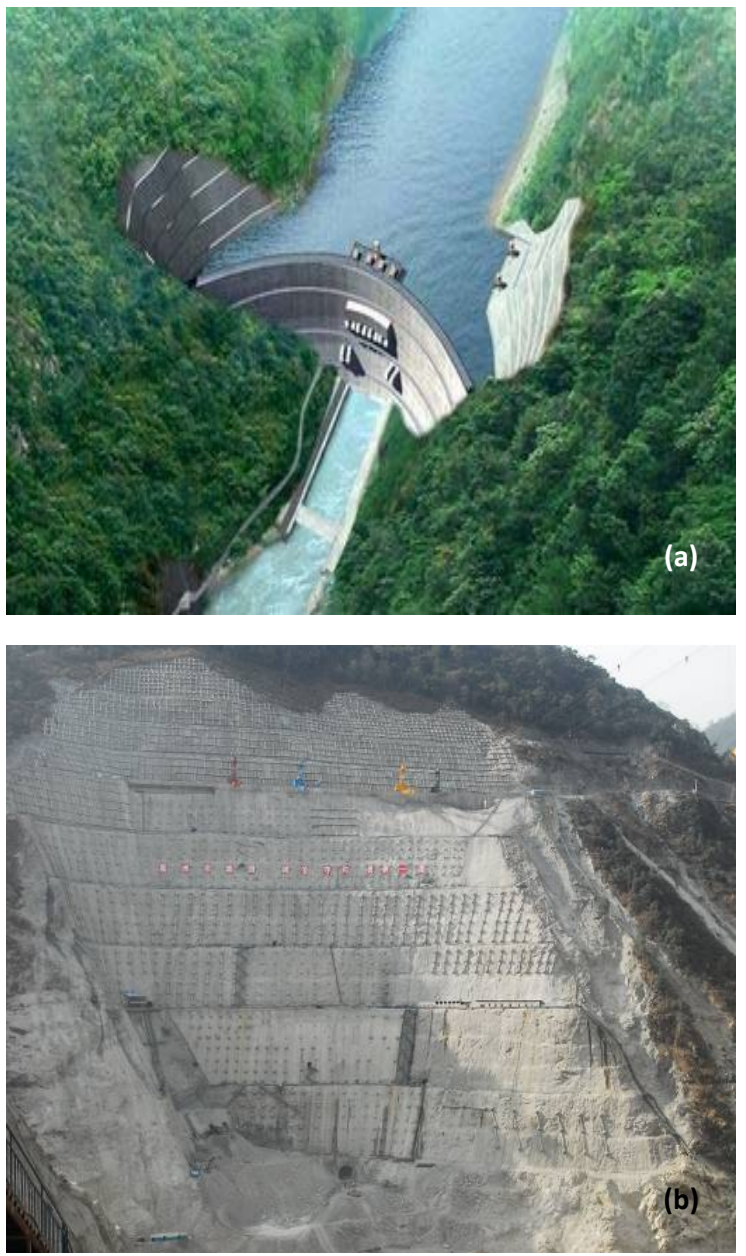

Fig. (2). Geomorphic photograph of the dam site (a) The layout of key water control, and (b) The right bank slope after excavation.

velocity field. The failure zones are thus determined. Meanwhile, the energy release and magnitude of microseismic events can be calculated by the duration of seismic phase, and the areas with high-frequency microseismic events can be identified and delineated with threedimensional geological map.

Assuming that all sensors are installed in a homogeneity and isotropic medium, namely with $\mathrm{P}$ wave having the same velocity at every direction. Then the minimum duration between hypocenters and sensors can be described as follow:

$t_{i}-t_{0}=\frac{\sqrt{\left(x_{0}-x_{i}\right)^{2}+\left(y_{0}-y_{i}\right)^{2}+\left(z_{0}-z_{i}\right)^{2}}}{v\left(x_{0}, y_{0}, z_{0}\right)}$

Where $x_{0}, y_{0}$ and $z_{0}$ are the hypocenter coordinates, $t_{0}$ is the time of commencement, $x_{i}, y_{i}$ and $z_{i}$ are the coordinates of the $i$ th sensor, $t_{i}$ is the time of $\mathrm{P}$ wave arriving at the $i$ th sensor, $v\left(x_{0}, y_{0}, z_{0}\right)$ is the velocity of $\mathrm{P}$ wave. There are four unknown parameters in equation (1), so data acquisition from at least four sensors is necessary to solve the equation. Twenty four equations similar to formula (1) can be listed if twenty four sensors are used to record microseismic signals in the right bank rock slope.
Theoretically speaking, it would be better if errors for seismic source localization are minimized. Several schemes of sensor networking should be designed and compared in order to get a minimum source localization error. However, as we know, there are many factors influencing the sensor arrangement in high rock slope, particularly in some complex hydroelectric projects. For example, the various tunnels, maintenance modes of tunnels, the degree of rock mass integrity, cable lengths, etc. Meanwhile, some random effects impacting seismic source location will be considered while checking location error, including errors in read-in $\mathrm{P}$ wave arrival time and velocity induced by characteristics of various rock masses. Assuming one point $h_{0}=\left(x_{0}, y_{0}, z_{0}\right)$ in the scope of sensor array is the location of hypocenter, and then the arrival time of $\mathrm{P}$ wave under random influences will be defined as:

$t_{i}=\frac{L_{i}}{\left(V_{i}\right)_{\text {rand }}}+\left(\delta_{t_{i}}\right)_{\text {rand }}$

Where $\left(V_{i}\right)_{\text {rand }}$ is the realistic velocity between the $i$ th sensor and $h_{0},\left(\delta_{t_{i}}\right)_{\text {rand }}$ is the random read-in error of $\mathrm{P}$ wave arrival time. If the sensor arrangement plane has been determined, Powell algorithm will be used to solve nonlinear least-square solution $h_{0}^{\prime}=\left(x_{0}^{\prime}, y_{0}^{\prime}, z_{0}^{\prime}\right)$, and location error will be determined as the linear distance between the realistic location and solving position:

$$
D_{x y z}=\sqrt{\left(x_{0}-x_{0}^{\prime}\right)^{2}+\left(y_{0}-y_{0}^{\prime}\right)^{2}+\left(z_{0}-z_{0}^{\prime}\right)^{2}}
$$

After finite operation to $h_{0}$ (number of times $N>1000$ ), positioning error of $h_{0}$ will be defined as mean error:

$\sigma_{h_{0}}=\sum_{i=1}^{N}\left(D_{x y z}\right)_{i} / N$

Based on such principles above, twenty four accelerometers have been installed at different tunnels inside the right bank rock slope by considering geological limitations on-site (there are three sensors to be installed later on due to the limitation of tunnel condition). The final optimal arrangement of sensor networking is thus obtained as shown in Fig. (3). Meanwhile, the location error analysis after optimal design of sensor networking is investigated by using ESG related programs, as illustrated in Fig. (4). It can be observed that microseismic source location error is less than $15 \mathrm{~m}$ in the scope of sensor array, which preliminarily validates microseismic monitoring system presented here has a high positioning accuracy. The scope of the sensor array can meet the global monitoring of deep rock mass deformation from upstream to downstream of the rock slope as shown in Fig. (4a).

\section{MICROSEISMIC MONITORING SYSTEM}

The constitution of the microseismic monitoring system at the right bank rock slope of Dagangshan Hydropower Station is shown in Fig. (5). The installation namely Hyperion Full Waveform consists of Hyperion digital signal processing system (Fig. (5a)), Paladin digital signal 


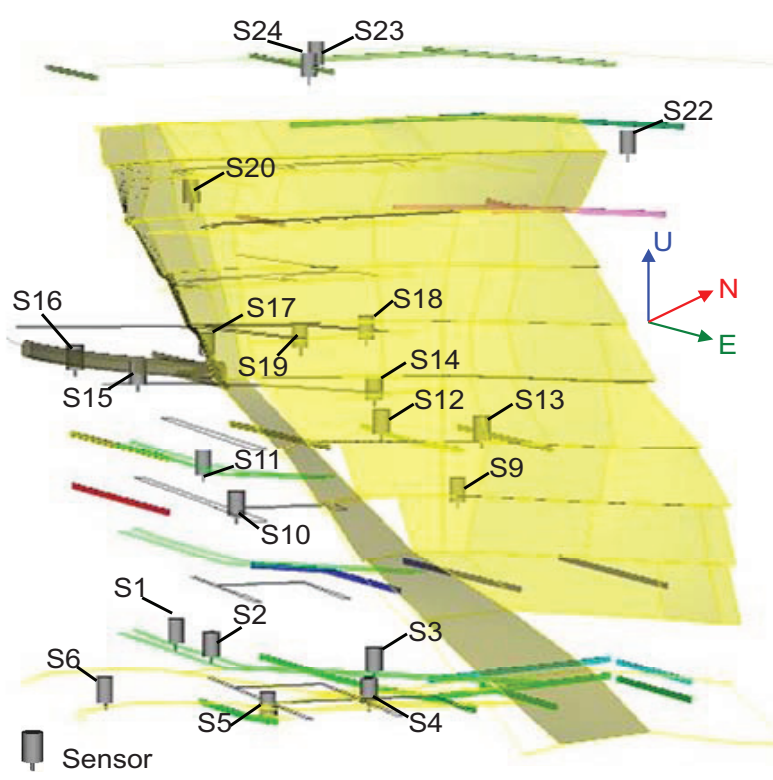

Fig. (3). Spatial arrangement diagram of sensors at eleven elevations.

acquisition system (Fig. (5b)), 24 uni-axial acceleration transducers deployed in boreholes drilled from the sidewalls of different tunnels inside the right bank slope (three sensors No.7, 8, 21 to be installed later on due to the limitation of tunnel condition) (Fig. (5c)), and a three-dimensional visualization system namely MMS-View (Fig. (5d)) based on remote wireless transmission developed by Dalian Mechsoft (Mechanics Software) Co. Ltd., China. The system presented here can acquire plenty of hypocenter parameters of microseismic event such as tempo-spatial data, location error, magnitude, energy, etc, with filtering processing conducted to the recorded data. It can also provide complete waveforms and wave spectrum analytical graph for clients. Furthermore, types of microseismic events can be identified automatically and noisy events can be eliminated through filtering processing, threshold configuration and bandwidth demodulation [3].

Fig. (6) schematically illustrates the structure of microseismic monitoring system. This network topology consists of 24 acceleration transducers, four substations (named Paladin), one on site monitoring control center, one remote calculation analysis and prediction center in Dalian, one center for chief engineer, and a number of communication cables connected with the centers shown above. Each substation connects four to six sensors which are typically uniaxial acceleration transducer. All of the four substations were installed in the observation station which was built at $1135 \mathrm{~m}$ level platform. The station can be suitable for workers to preserve at any time. Sensors were connected to the Paladins using copper twisted-pair cables. One Paladin was connected to other Paladins using optical fiber cables. Generally speaking, microseismic monitoring system was typically configured using twisted pair cable, fiber optics, radio telemetry or a hybrid combination of the above. Total 24 acceleration sensors can cover a volume of $400 \mathrm{~m}$ length, $400 \mathrm{~m}$ width and $600 \mathrm{~m}$ depth. Microseismic signals are
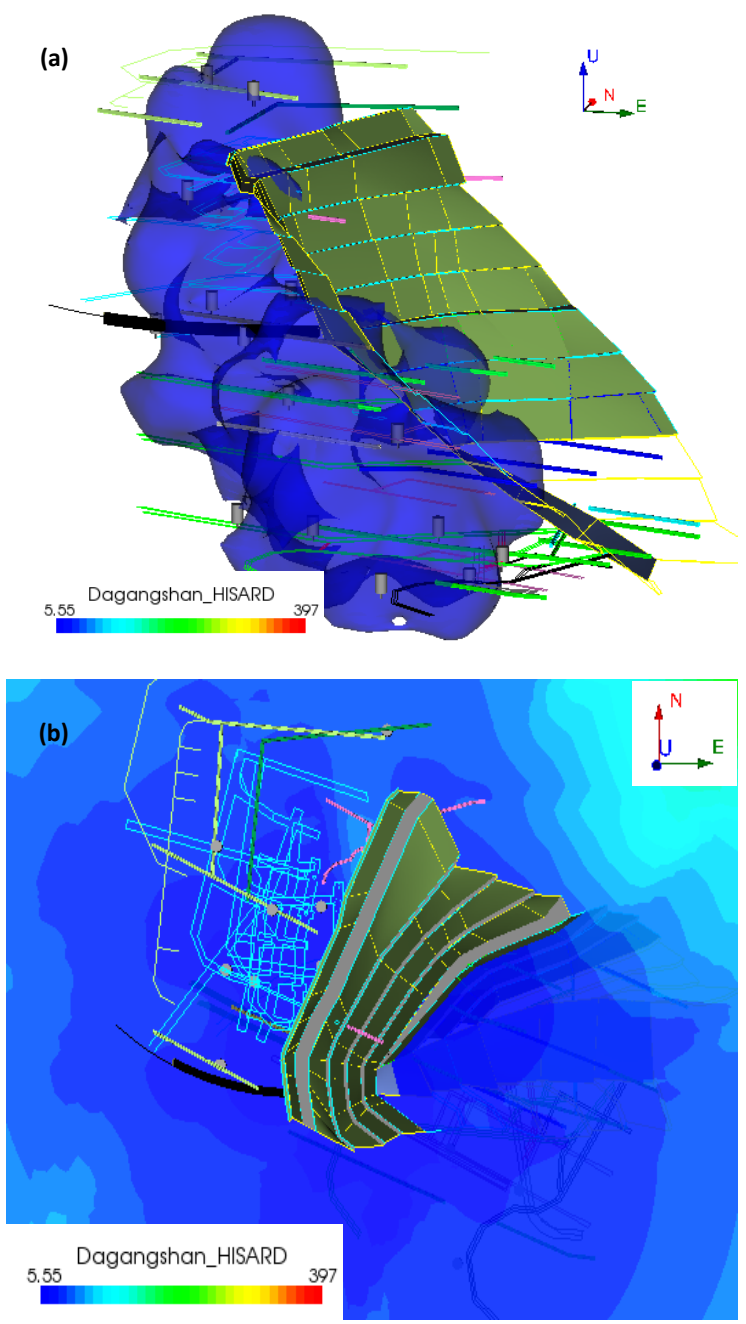

Fig. (4). Location error analysis after optimal arrangement of sensors: (a) From a whole perspective, and (b) north-easting plane looking down at $1135 \mathrm{~m}$ level. Different colors represent various seismic source location errors.

transmitted to the data analysis system through the data acquisition system (Paladins), as shown in Fig. (5d). Because of the geographical limitations, there is no GPS signal utilized as a time source. The Paladin units rely on a pulse per second (PPS) signal originated from the Paladin Timing Source over the network. This can allow the data from each Paladin to be accurately time-stamped, ensuring multiple units to be synchronized [4,6]. With respect to the fundamental principle and technical parameters of microseismic monitoring technique, there are some systematic introductions in the related references $[3,13]$.

\section{ERROR ANALYSIS OF MICROSEISMIC SOURCE LOCATION AND TYPICAL WAVEFORMS}

\subsection{Wave Velocity Testing}

There are two sources causing positioning error of microseismic monitoring system. They are system signal processing and natural geological conditions of the rock slope [18]. The wave velocity influences the first break time 

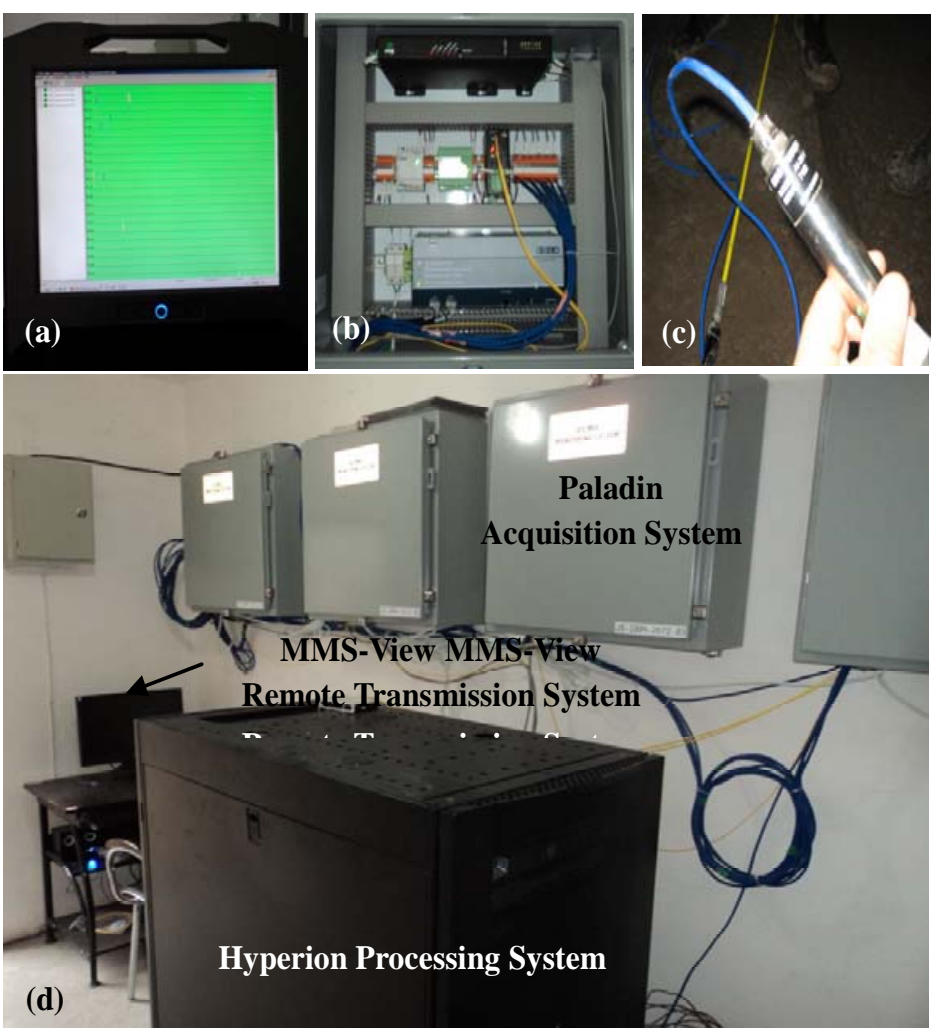

Fig. (5). Constitution of micro-seismic monitoring system: (a) Hyperion digital signal processing system, (b) Paladin digital signal acquisition system, (c) acceleration transducer, and (d) the center of the site monitoring system.

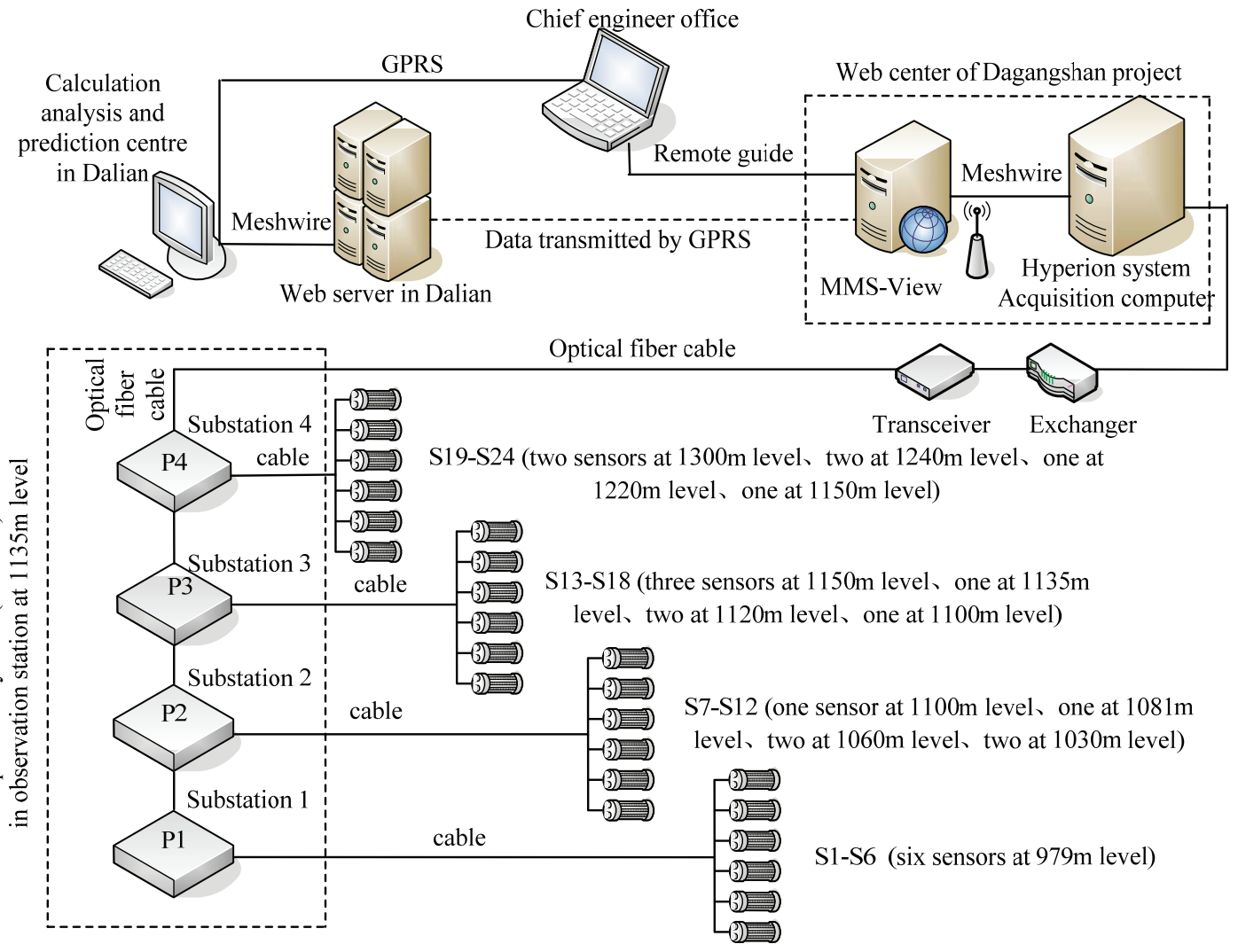

Fig. (6). Network topology of microseisimic monitoring system. 
that elastic wave arrives to sensors. Therefore, wave velocity configured in the monitoring system has a great influence on microseismic source location. In this respect, wave velocity of rock mass within the monitoring scope must be calibrated before testing the positioning error of the system. The mean velocity of elastic wave is first determined as $4500 \mathrm{~m} / \mathrm{s}$ according to wave velocity tests of rock samples on-site. Then the wave velocity of blast tests is calculated inversely and adjusted through data analysis program developed by ESG Canada Inc. The study presented here utilized excavation blasts data to preliminarily investigate the velocity of the system. The waveform of the first blast test recorded is shown as Fig. (7), which occurred inside the drainage tunnel of the dam foundation at $1081 \mathrm{~m}$ level on 04 : 25: 41, May 7, 2010. The testing results show that the mean velocity of $P$ wave and $S$ wave are $4400 \mathrm{~m} / \mathrm{s}$ and $2540 \mathrm{~m} / \mathrm{s}$ respectively in the scope of monitoring, which coincide with testing results of wave velocities on-site. The wave velocities can be then used to locate microseismic events.

After calibration of wave velocity inside rock mass in the scope of monitoring, three localization tests using artificial blasts method were performed in order to check positioning accuracy of the microsesimic monitoring installation at the right bank slope. In order to trigger more sensors to receive the signals, the fixed artificial blasting tests were located at the working face of the drainage tunnel at $1081 \mathrm{~m}$ level, which was nearby the center of the scope of sensor array. The coordinates of three artificial blasting tests location and their positioning recorded by the monitoring system are shown as Table 1. The results of blasting tests show that microseismic source location error is less than $10 \mathrm{~m}$ in the scope of the sensor array. This validates that the accuracy of the microseismic monitoring system installed at the right bank rock slope is high. Fig. (8) shows the spatial comparison between an artificial blast test location and its positioning result recorded by the system.

\subsection{Waveform Identification and Analysis}

Through field observation and investigation, the preliminary events recorded by the microseismic monitoring system at the right bank slope are classified into three main types: rock micro-fracture events, excavation blasting events, vibration and noisy events [3]. Fig. (9) shows the typical waveform of microseismic event. It can be observed that such waveforms are very smooth with amplitude range from dozens of $\mathrm{mV}$ to hundreds of $\mathrm{mV}$, magnitude distribution nearby -1.2 , and energy release around about $10^{2}$ Joule. The waveform of blasting tests is shown above in Fig. (7). It occurred inside the drainage tunnel of the dam foundation at 1081m level on 04: 25: 41, May 7, 2010. The sensor No.11 (S11-1081m), which was close to the shot point, picked up the elastic wave induced by blasting tests at first. The

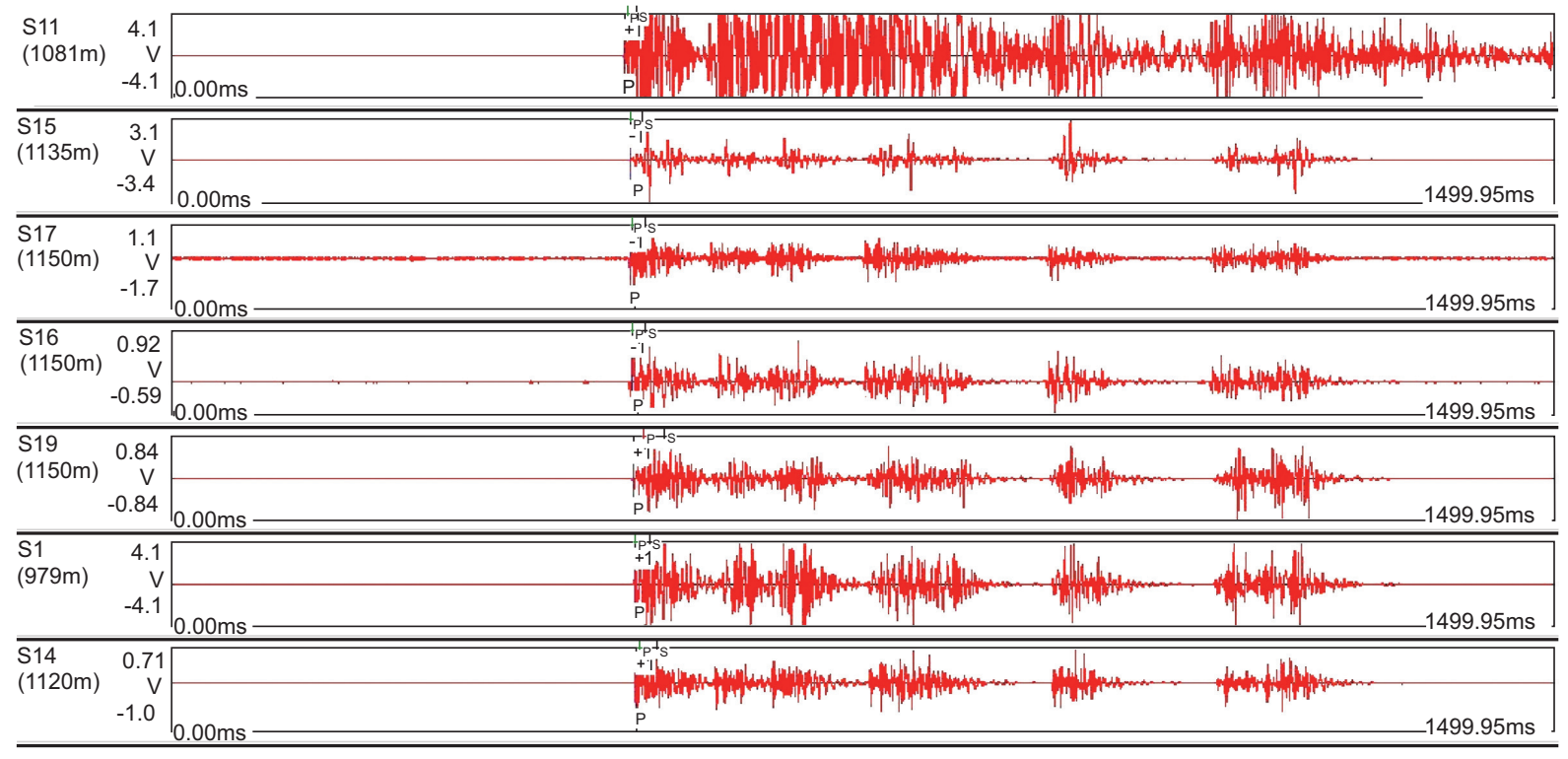

Fig. (7). Waveform of the first artificial blast recorded by the system.

Table 1. Comparison of Coordinates of Artificial Blasting with Those of Microseismic Monitoring Localization (in 2010)

\begin{tabular}{|c|c|c|c|c|c|c|c|c|c|c|c|c|c|}
\hline \multirow{2}{*}{ Order } & \multirow{2}{*}{$\begin{array}{l}\text { Blast } \\
\text { Date }\end{array}$} & \multirow{2}{*}{$\begin{array}{l}\text { Blast } \\
\text { Time }\end{array}$} & \multirow{2}{*}{$\begin{array}{l}\text { Height } \\
\text { /m }\end{array}$} & \multicolumn{3}{|c|}{ Blast Test Coordinates/m } & \multicolumn{3}{|c|}{ Locating Coordinates/m } & \multicolumn{3}{|c|}{ Error/m } & \multirow{2}{*}{$\begin{array}{l}\text { Absolute } \\
\text { Error/m }\end{array}$} \\
\hline & & & & $X$ & $\boldsymbol{Y}$ & $Z$ & $X$ & $\boldsymbol{Y}$ & $Z$ & $X$ & $\boldsymbol{Y}$ & $Z$ & \\
\hline 2 & $05-07$ & 19:08:52 & 1081 & 520829.4 & 3259169.8 & 1082.8 & 520823.9 & 3259173.5 & 1080.8 & 5.5 & 3.7 & 2.0 & 6.9 \\
\hline
\end{tabular}



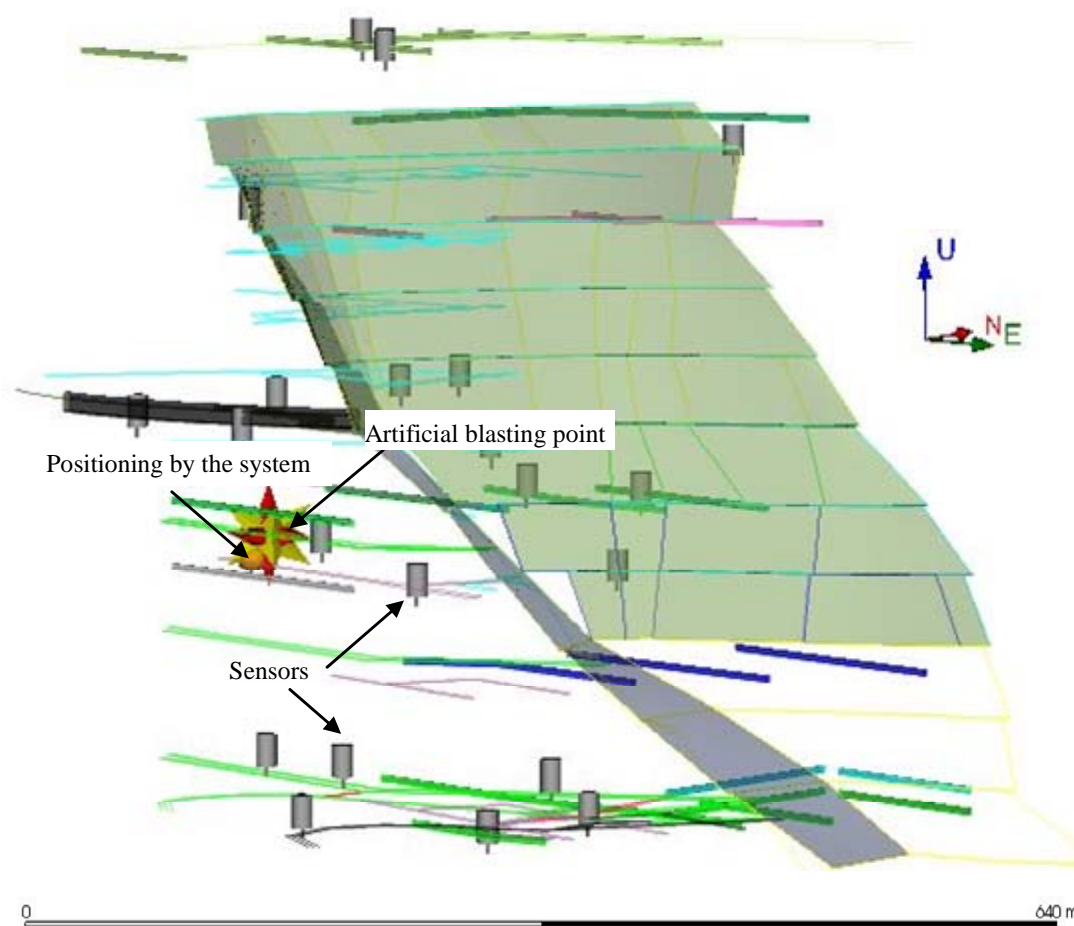

Fig. (8). Spatial comparison between one artificial blasting location and its positioning result recorded by the system.

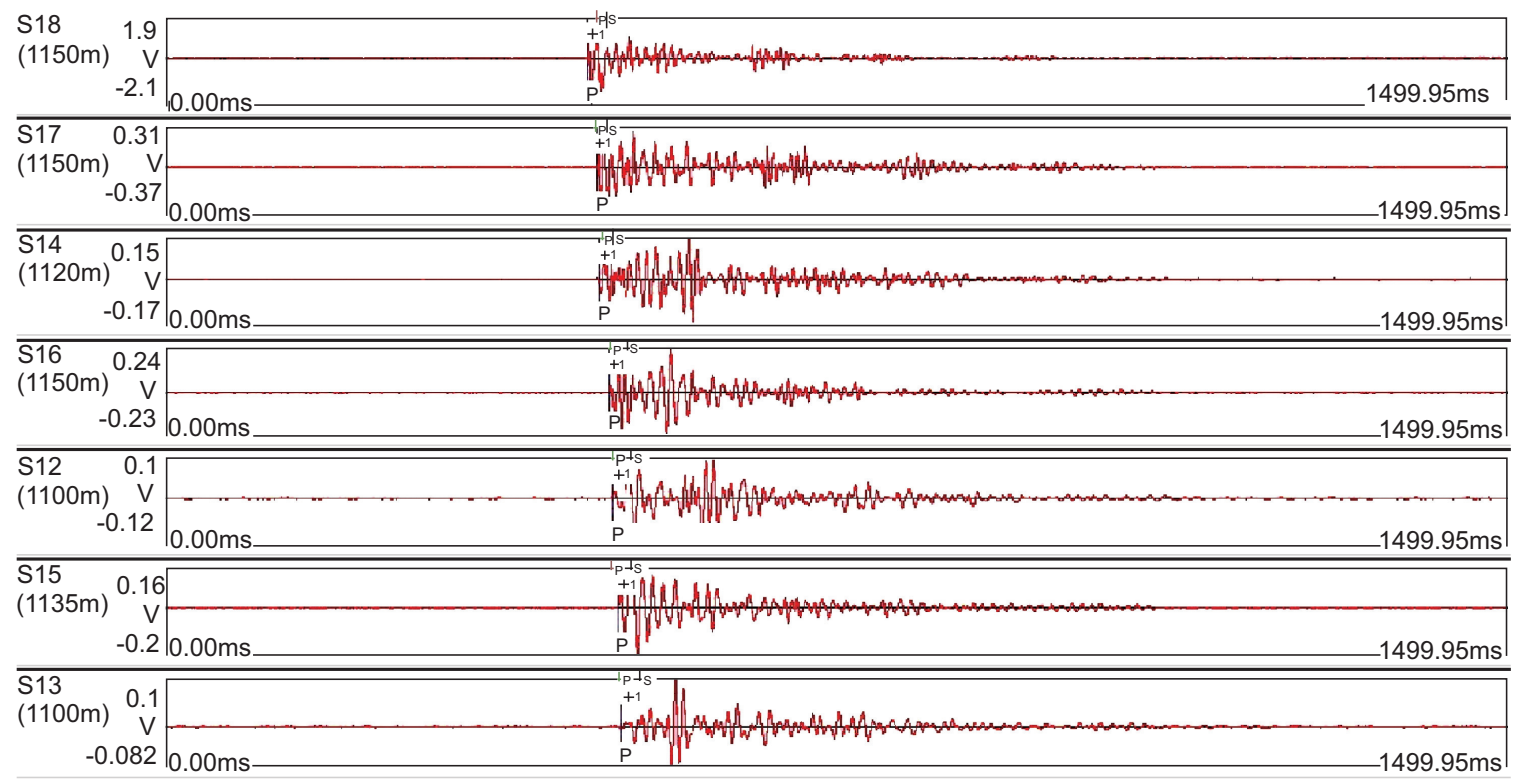

Fig. (9). Waveform of a typical microseimic event.

amplitude of the blasting event was about $4.1 \mathrm{~V}$ and the moment magnitude was -0.91. Fig. (10) shows the waveforms of different machinery vibration and noise. The characteristics of such waveforms are repeat shaking along time shaft and stripped. In order to verify the installation accuracy of the sensors, artificial tap tests corresponding to each sensor are performed as shown in Fig. (10a). It can be seen that the amplitude of sensor No.5 (S5-979m) in acquisition interface is greatly higher than other sensors when knocking rock mass nearby the sensor No.5 at $979 \mathrm{~m}$ level. The results demonstrate that the coordinates for each sensor input into the system are correct.

\section{PRELIMINARY MONITORING RESULTS AND DISCUSSION}

After filtering out the noisy events, a dataset of 255 microseismic events with moment magnitudes ranging from -1.8 to -0.4 was recorded during its 2 -month monitoring 
period. The microseismic data is available for further analysis. This research focuses on using microseismicity as an exploration tool to investigate early warning of slope instability and evaluate the main characteristics of seismic activity during excavation of the rock slope and the tunnels inside the slope. Fig. (11) presents the rate graph of microseismic event. It can be seen that the daily rate of events ranges from 1 to 6 with activities of small bursts. The mean rate of events is 5 per day. The spatial distribution of the seismic source locations recorded during the selected period is presented in Fig. (12). It can be noted from the figure that the hypocenters of the microseismic events form a cluster elongated near the working face of the drainage tunnel at $1081 \mathrm{~m}$ level. According to the construction condition on-site, the cluster of microseismic events is caused by disturbance of excavation blasting in the drainage tunnel at $1081 \mathrm{~m}$ level (see Fig. (12a)). Therefore, clustering of microseismic events can reflect the processes of construction directly and delineate the micro-fracture regions in deep rock mass preliminarily at the right bank slope.

The monitoring results indicate that the clustering of microseismic events caused by excavation disturbance can reflect the progress of on-site construction very well. Thus, it can also reveal the tendency of the stress change and stress transfer caused by construction disturbance in advance. This study indicates that the design and implementation of the

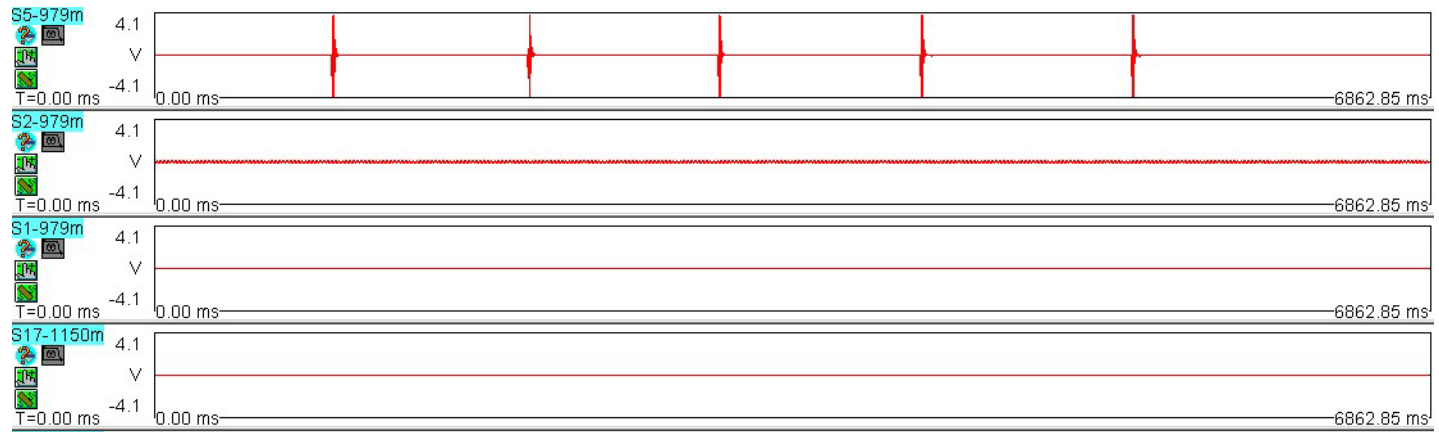

(a)

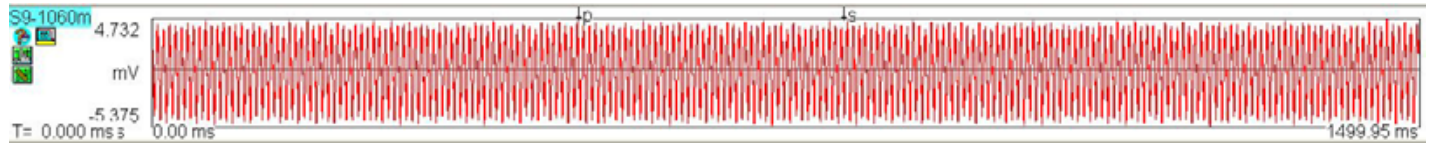

(b)

Fig. (10). Waveforms of vibration and noise: (a) Waveform of tap tests, and (b) Waveform of electricity interference.

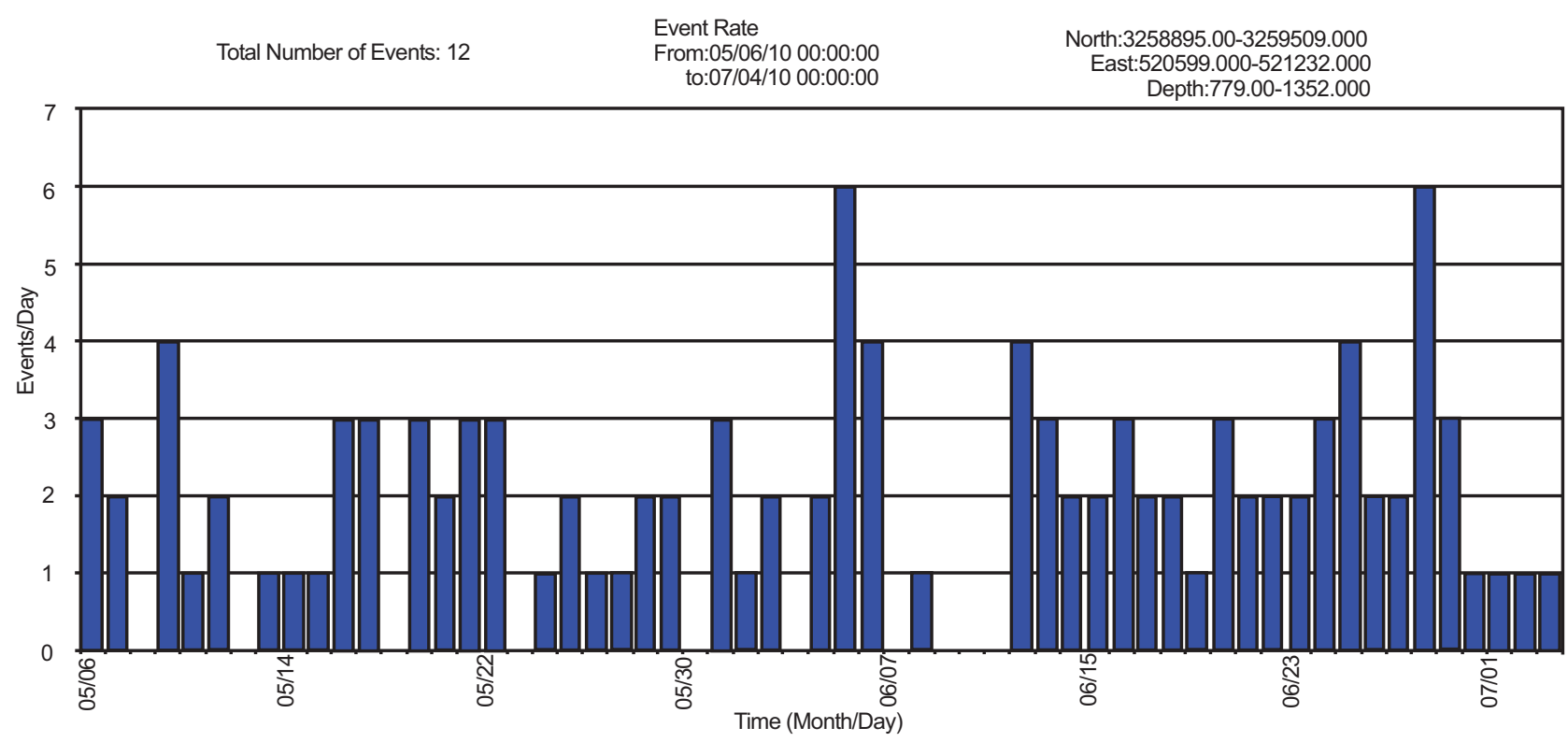

Fig. (11). The temporal distribution of microseismic events. 

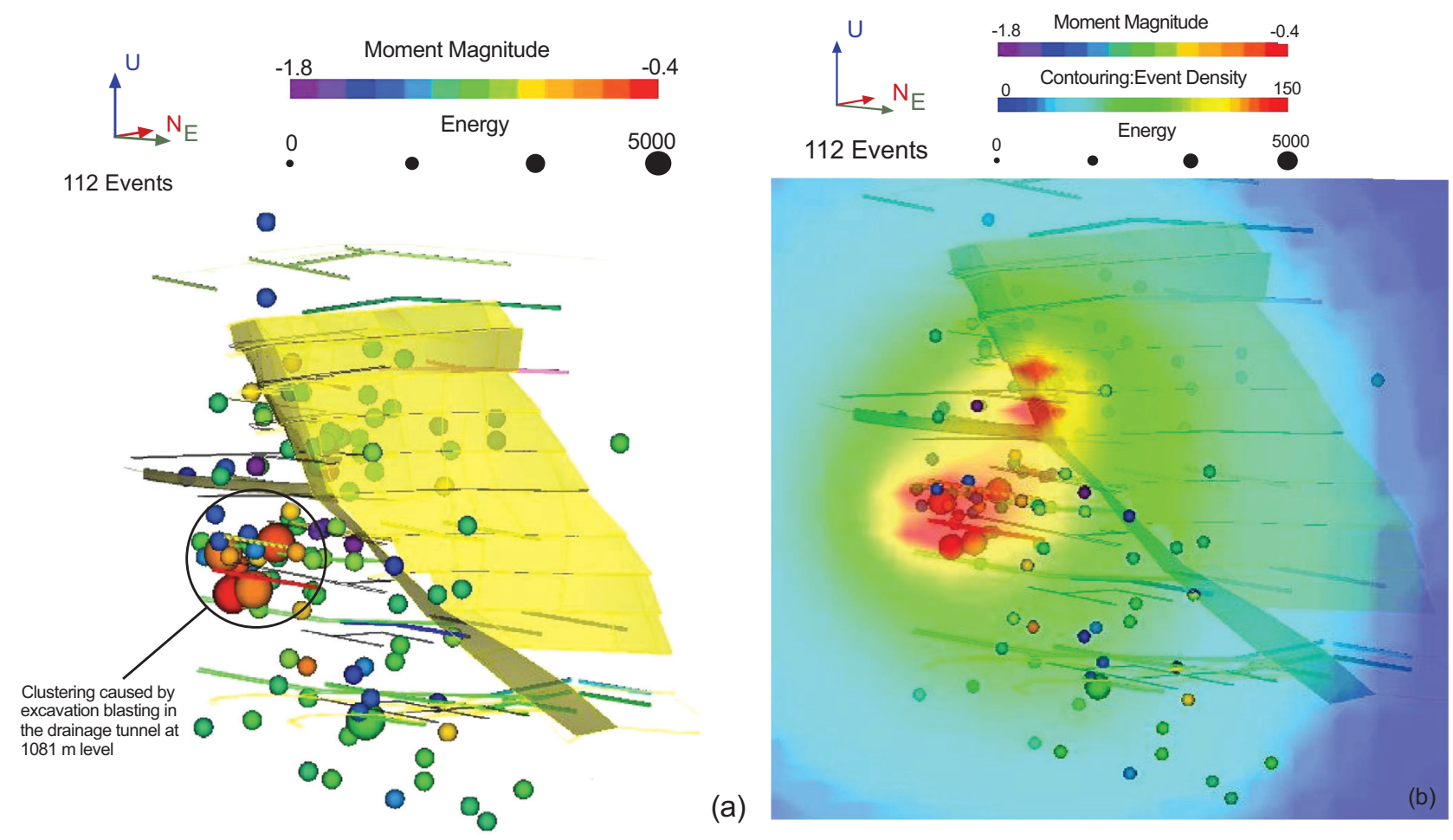

Fig. (12). The spatial distribution of microseismic events at the right slope: (a) spatial distribution of microseismic events, and (b) density contour of microseismic events.

microseismic monitoring system can meet the global monitoring of deep rock mass deformation at the right bank slope. The successfully deployed monitoring system can identify and delineate the regions of micro-fracturing induced by excavation in deep rock mass. It provides a reference for later excavation and reinforcement of the right bank rock slope later on.

\section{CONCLUSIONS}

In the present study, a high-precision microseismic monitoring system was installed at the right bank rock slope in Dagangshan hydropower station, southwest China from May $5^{\text {th }} 2010$. Optimal design of the microseismic monitoring networking was performed based on $\mathrm{P}$ method and Powell algorithm. The error analysis of seismic source localization was also conducted through artificial blasting tests. Combined with observation on-site, typical waveforms identification and analysis were investigated. The following conclusions can thus be drawn,

(1) The design and implementation of the optimal sensor array can meet the global monitoring requirement of deep rock mass deformation inside the right bank slope. The second high-precision microseismic monitoring system applied to analyze stability of rock slope in China has been implemented successfully.

(2) The positioning accuracy of the monitoring system has been adjusted according to artificial fixed blasting tests. The results show that the error of seismic source location is less than $10 \mathrm{~m}$ in the scope of the sensor array. There- fore, high-accuracy positioning has been realized in the application to strong-weathering rock mass.

(3) Identification and investigation of different types of waveforms has been performed based on the on-site construction condition. It shows that the occurrence of microseismicity is closely associated with the on-site construction processes. The investigation of miciroseismicity can very well reflect the deep rock deformation caused by excavation disturbance.

(4) Rock failure occurring in rock slope is mainly caused by high stress concentration and stress migration induced by construction disturbance. This is the main cause of microseismicity. Therefore, the micro-fracture inside the deep rock mass at the regions of interest will increase along with excavation of the right bank slope below 1060 $\mathrm{m}$ level. The prediction and explanation of deep rock mass deformation can be performed on the basis of increasing tendency of microseismic events.

The studies in this paper are preliminary research. With accumulation of microseismic data recorded and extension of excavation scale below $1060 \mathrm{~m}$ level at the right bank slope, further investigation on these results will be extensively studied through analysis of more rock failure cases occurring in the deep rock mass.

\section{ACKNOWLEDGEMENTS}

Financial supports from the National Natural Science Foundation of China (Grant Nos. 10672028, 50820125405, and) and National Basic Research Program of China 
(973 Program, Grant No. 2007CB209400) are greatly acknowledged.

\section{REFERENCES}

[1] M. Cai, P. K. Kaiser, and C. D. Martin, "Quantification of rock mass damage in underground excavations from microseismic event monitoring," Int. J. Rock. Mech. Min. Sci., vol. 38, pp. 1135-1145, 2001.

[2] C. C. Graham, S. Stanchits, I. G. Main, and G. Dresen, "Comparison of polarity and moment tensor inversion methods for source analysis of acoustic emission data," Int. J. Rock. Mech. Min. Sci., vol. 47, pp. 161-169, 2010.

[3] N. W. Xu, C.A. Tang, C. Sha, Z. Z. Liang, J. Y. Yang, and Y. Y. Zou, "Microseismic monitoring system establishment and its engineering applications to left bank slope of Jinping I Hydropower Station," Chinese. J. Rock. Mech. Eng., vol. 29, pp. 915-925, 2010.

[4] C. Yang, Z. Luo, G. Hu, and X. Liu, "Application of a microseismic monitoring system in deep mining," J. Univ. Sci. Technol. B.: Mineral Metallurgy Materials (Eng Ed), vol. 14, pp. 6-8, 2007.

[5] M. Ge, "Efficient mine microseismic monitoring," Int. J. Coal. Geol., vol. 64, pp. 44-56, 2005.

[6] T. I. Urbancic and C. I. Trifu, "Recent advances in seismic monitoring technology at Canadian mines," J. Appl. Geophys., vol. 45, pp. 225-237, 2000.

[7] S. Baisch, R. Vörös, E. Rothert, H. Stang, R. Jung, and R. Schellschmidt, "A numerical model for fluid injection induced seismicity at Soultz-sous-Forêts," Int. J. Rock. Mech. Min. Sci., vol. 47, pp. 405-413, 2010.

[8] F. H. Cornet, "Introduction to the special section on induced seismicity," Int. J. Rock. Mech. Min. Sci., vol. 44, pp. 1077-1078, 2007.

[9] A. Jupe, R. Jone, S. Wison, and J. Cowles, "The role of microearthquake monitoring in hydrocarbon reservoir management," presented at the Proceedings of 2000 Society of Petroleum
Engineers Annual Technical Conference and Exhibition, Dallas, Texas, 2000.

[10] A. Hirata, Y. Kameoka, and T. Hirano, "Safety management based on detection of possible rock bursts by $\mathrm{AE}$ monitoring during tunnel excavation," Rock. Mech. Rock. Eng., vol. 40, pp. 563-576, 2007.

[11] T. Li, M. F. Cai, and M. Cai, "A review of mining-induced seismicity in China," Int. J. Rock. Mech. Min. Sci., vol. 44, pp. 1149-1171, 2007.

[12] S. L. Li, "Discussion on microseismic monitoring technology and its applications to underground projects," Chinese J. Underground Space. Eng., vol. 5, pp. 122-128, 2009.

[13] N. W. Xu, C. A. Tang, and Z. Z. Liang, "Numerical analysis of surrounding rock stabiltiy on the influence of different geometry," in Controlling Seismic Hazard and Sustainable Development of Deep Mines: 7th International Symposium on Rockburst and Seismicity in Mines (Rasim7), Vol. 1-2, 2009, pp. 1263-1268.

[14] C. A. Tang, J. M. Wang, J. J. Zhang, "Preliminary engineering appliction of microseismic monitoring technique to rockburst prediction in tunneling of Jinping II project," J. Rock. Mech. Geotech. Eng., vol. 2, pp. 193-208, 2011.

[15] J. D. Shao, W. G. Li, W. Z. Deng, K. J. Zhu, M. Z. Du, C. Huang, J. H. Zeng, "Feasibility study report on Dagangshan Hydropower Station at Dadu River, Sichuan Province," HydroChina Chengdu Engineering Corporation, Chengdu, 2006.

[16] S. L. Li, X. G. Yin, W. D. Zheng, and T. Cezar, "Research of multi-channel microseismic monitoring system and its application to Fankou lead-zinc mine," Chinese J. Rock. Mech. Eng., vol. 24, pp. 2048-2053, 2005.

[17] Z. L. Mu, L. M. Dou, S. Y. Gong, and A. Y. Cao, "Networking design of SOS micro-seismic monitoring for mine and error analysis of seismic resource orientation," Coal. Min. Tech., vol. 14, pp. 8-14, 2009.

[18] Z. Yang, R. Yu, R. Guo, C. Yang, and L. Wang, "Application of microseismic monitoring to deep mines," Chinese J. Rock. Mech. Eng., vol. 27, pp. 1066-1073, 2008.

(C) Xu et al.; Licensee Bentham Open.

This is an open access article licensed under the terms of the Creative Commons Attribution Non-Commercial License (http://creativecommons.org/licenses/_by-nc/3.0/) which permits unrestricted, non-commercial use, distribution and reproduction in any medium, provided the work is properly cited. 